\title{
28 Research Square \\ Efficacy of High-flow Nasal Cannula Oxygen Therapy in Patients with Mild Hypercapnia
}

\section{Lingling Su}

Jiangyan TCM Hospital Affiliated to Nanjing University of Chinese Medicine

\section{Qinyu Zhao}

Colldge of Engineering and Computer Science, Australian National University

Taotao Liu ( $\nabla$ taotao20022000@163.com )

Beijing Hospital https://orcid.org/0000-0002-2898-4334

\section{Yujun Xu}

Munichioninistr. 15, 81377 Munich

\section{Weichun Li}

Jiangyan TCM Hospital Affiliated to Nanjing University of Chinese Medicine: Suzhou Hospital of

Traditional Chinese Medicine

\section{Aiping Zhang}

Jiangyan TCM Hospital Affiliated to Nanjing University of Chinese Medicine

\section{Research Article}

Keywords: High-flow nasal cannula, Hypercapnia, Non-invasive mechanical ventilation, MIMIC

Posted Date: June 17th, 2021

DOl: https://doi.org/10.21203/rs.3.rs-616727/v1

License: (c) (1) This work is licensed under a Creative Commons Attribution 4.0 International License.

Read Full License 


\section{Abstract}

Objectives: To investigate the indications of high-flow nasal cannula (HFNC) oxygen therapy among patients with mild hypercapnia and to explore the predictors of intubation when HFNC fails.

Methods: This retrospective study was conducted based on the Medical Information Mart for Intensive Care IV (MIMIC-IV) database. Adult patients with mild hypercapnia $\left(45<\mathrm{PaCO}_{2} \leq 60 \mathrm{mmHg}\right)$ received either HFNC or noninvasive ventilation (NIV) oxygen therapy. Propensity score matching (PSM) was implemented to increase between-group comparability. The Kaplan-Meier method was used to estimate overall survival and cumulative intubation rates, while 28-day mortality, 48-hour and 28-day intubation rates were compared using the Chi-square test. The predictive performances of $\mathrm{HR} / \mathrm{SpO}_{2}$ and the $\mathrm{ROX}$ index (the ratio of $\mathrm{SpO}_{2} / \mathrm{FiO}_{2}$ to respiratory rate) at 4 hours were assessed regarding $\mathrm{HFNC}$ failure, which was determined if intubation was given within 48 hours after the initiation of oxygen therapy. The area under the receiver operating characteristic curve (AUC) for $\mathrm{HR} / \mathrm{SpO}_{2}$ and the ROX index were calculated and compared.

Results: A total of 524,520 inpatient hospitalization records were screened, 106 patients in HFNC group and 106 patients in NIV group were successfully matched. No significant difference in 48-hour intubation rate between the HFNC group and the NIV group ( $14.2 \%$ vs. $8.5 \%, \mathrm{P}=0.278)$; patients receiving HFNC had higher 28 -day intubation rate ( $26.4 \%$ vs. $14.2 \%, P=0.029)$, higher 28 -day mortality $(17.9 \%$ vs. $8.5 \%$, $\mathrm{P}=0.043$ ), longer ICU length of stay (4.4 vs. 3.3 days, $\mathrm{P}=0.019)$, compared to those of NIV group. The AUC of $\mathrm{HR} / \mathrm{SpO}_{2}$ at 4 hours after the initiation of HFNC yielded around 0.660 for predicting 48 -hour intubation, greater than that of the ROX index with an AUC of $0.589(P<0.01)$.

Conclusions: HFNC therapy cannot completely replace NIV for patients with mild hypercapnia. As opposed to the ROX index, a modest, yet improved predictive performance is demonstrated using $\mathrm{HR} / \mathrm{SpO}_{2}$ in predicting the failure of HFNC among these patients.

\section{Introduction}

High-flow nasal cannula (HFNC) oxygen therapy has been widely applied, delivering a heated and humidified high-flow air-oxygen mixture, which has been shown to outperform conventional oxygen therapy [1-3]. Several clinical trials have suggested that the effect of HFNC in patients with hypoxemia is not inferior to that of noninvasive ventilation (NIV) [4-6]. However, only a few studies have reported that HFNC can achieve the same therapeutic effect as NIV among patients with mild hypercapnia [7, 8]. Whether HFNC can replace NIV in treating mild hypercapnia is still unclear, while predictors at an early stage for the outcome of oxygen therapy remain to be explored.

This study retrospectively analyzed patients derived from the Medical Information Mart for Intensive Care IV (MIMIC-IV) database to investigate the indications of HFNC for patients with mild hypercapnia. The 
predictive performance of physiological parameters for the outcome of high flow therapy was also evaluated.

\section{Methods}

\section{Patients}

Patients admitted to ICU from 2008 to 2019 were identified in the MIMIC-IV database. The inclusion criteria were as follows: over 18 years old; with mild hypercapnia $\left(45<\mathrm{PaCO}_{2} / \mathrm{FiO}_{2} \leq 60 \mathrm{mmHg}\right)$ before HFNC or NIV. The exclusion criteria were as follows: tracheotomy; without intubation plan; having received both HFNC and NIV before intubation.

Source of data and ethics approval

This retrospective study was conducted based on the MIMIC-IV database[9], consisting of comprehensive and high-quality data of patients admitted to the intensive care unit (ICU) at the Beth Israel Deaconess Medical Center between 2008 and 2019 with pre-existing institutional review board approval. One author (QZ) obtained access to the database and was responsible for data extraction.

Study design

Patients were treated with either HFNC or NIV (continuously or intermittently). The following data were extracted from the database: age, sex, body mass index (BMI), Charlson Comorbidity Index, Simplified Acute Physiology Score II (SAPS-II) at ICU admission, physiological parameters at baseline and within 24 hours after the initiation of oxygen therapy, as well as outcome measures including 28-day mortality, 48hour and 28-day intubation rate, and length of stay in ICU and in hospital. Patients were matched using a propensity score model. Treatment outcomes regarding mortality, intubation rates and length of stay between the HFNC and NIV groups were compared after propensity score matching (PSM).

$\mathrm{HR} / \mathrm{SpO}_{2}$ (the ratio of heart to pulse oxygen saturation) at 4 hours was used as a predictor for high flow treatment failure, defined as receiving intubation within 48 hours after the initiation of the treatment. Its predictive performance was compared with the 4-hour ROX index (the ratio of $\mathrm{SpO}_{2} / \mathrm{FiO}_{2}$ to respiratory rate) using the area under the receiver operating characteristic curve (AUC).

Statistical analysis

Variables with normal distributions were presented as means (SD) and were compared by independent samples $t$ test. Non-normally distributed variables were reported as medians [IQR], where the MannWhitney $U$ test was used. Categorical variables were described as percentages and were compared using the Chi-squared test or Fisher's exact test, when appropriate. The Kaplan-Meier method was applied to estimate the overall survival rate and cumulative intubation rate. 
Missing values were imputed by Multivariate Imputation by Chained Equations, following which a multivariate logistic regression model incorporating... was constructed to estimate a patient's propensity score for receiving HFNC. 1:1 nearest neighbor matching with a caliper width of 0.1 was then applied [10].

All statistical analyses were performed with $R$ (version 3.6.1), and a p value less than 0.05 was considered statistically significant.

\section{Results}

A total of 524,520 hospitalization records were screened, and 379 patients were included in this study, of which 133 patients received HFNC and 246 patients received NIV. After propensity score matching, there were 106 patients in the HFNC group and 106 patients in the NIV group, with a mean age of 68.8 and 66.1 years old, respectively. $\mathrm{PaCO}_{2}$ before oxygen therapy was $49.8[46.8,57.5] \mathrm{mmHg}$ in the HFNC group and $48.8[46.5,56.5] \mathrm{mmHg}$ in the NIV group. No statistically significant differences were identified in baseline characteristics regarding age, sex, BMI, SAPS II and Charlson score between the two groups (all P > 0.05).

There was no significant difference in 48-hour intubation rate between the HFNC group and the NIV group after PSM (14.2\% vs. 8.5\%, $P=0.278)$. However, patients on HFNC appeared to have higher 28-day intubation rate $(26.4 \%$ vs. $14.2 \%, P=0.029)$, had higher 28 -day mortality ( $17.9 \%$ vs. $8.5 \%, P=0.043)$, and stayed longer in ICU (4.4 vs. 3.3 days, $P=0.019$ ) as opposed to those receiving NIV therapy (Table 1 and Fig.1).

Heart rate and respiratory rate at 12 hours in the HFNC group significantly decreased ascompared with those at baseline (91.2 vs. 96.0 and 21.7 vs. 22.3, both $\mathrm{P}<0.05$ ). $\mathrm{PaCO}_{2}$ at 24-hour in the HFNC group significantly decreased compared to that at baseline ( 45.9 vs. $49.8 \mathrm{mmHg}, P<0.05$ ), while in the NIV group, $\mathrm{PaCO}_{2}$ at 12 -hour was significantly lower than that at baseline ( 46.0 vs. $\left.48.8 \mathrm{mmHg}, \mathrm{P}<0.05\right)$. (Table 2 and Fig.2)

Regarding the prediction for 48-hour intubation among patients in the HFNC group, the AUC of $\mathrm{HR} / \mathrm{SpO}_{2}$ at 4 hours after HFNC is greater than that of the ROX index $(0.660$ vs. $0.589, \mathrm{P}<0.01)($ Table 3 and Fig.3). An optimal cut-off point of $\mathrm{HR} / \mathrm{SpO}_{2}$ with a value of 1.08 was determined by the Youden index, resulting in a sensitivity of $57.1 \%$ and a specificity of $73.6 \% \otimes \mathrm{Fig} .4 \rrbracket$.

Data are presented as mean (standard deviation) or median [interquartile range] or number (\%)

Continuous variables were compared by independent samples t-test or Mann-Whitney U test, while categorical variables were compared using Chi-square test or Fisher's exact test, when appropriate.

Data are presented as mean (standard deviation) or median [interquartile range]. 
Continuous variables were compared by independent samples t-test or Mann-Whitney U test, while categorical variables were compared using Chi-square test or Fisher's exact test, when appropriate.

\section{Discussion}

High-flow oxygen therapy provides constant airflow and oxygen concentration, which has been found more effective than conventional oxygen therapies such as nasal catheter and mask oxygen [11-13]. For patients with mild to moderate hypoxemia, the effect of HFNC is not inferior to that of NIV $[5,6]$. Previous physiological studies have illustrated that high flow airflow can wash the nasopharyngeal dead space and produce a low level of $3-6 \mathrm{cmH}_{2} \mathrm{O}$ positive end-expiratory pressure [14-16], which is the theoretical basis for HFNC in the treatment of mild hypercapnia. A few studies have suggested that HFNC can replace NIV for patients with hypercapnia $[17,18]$, while it is generally not applicable to severe type 2 respiratory failure. However, the small sample sizes in these studies have left the specific indications for HFNC in the treatment of hypercapnia unclear.

More than 500,000 patients with MIMIC-IV data were screened and 379 patients with mild hypercapnia receiving either HFNC or NIV were included in our study. 28-day intubation rate and 28-day mortality in the HFNC group were higher than those in the NIV group after propensity score matching. Furthermore, the ICU length of stay in the HFNC group was longer than that in the NIV group. The insignificant difference in 48-hour intubation rate between the two groups may be a result of the insufficient event cases. Previous studies have shown that the effect of HFNC outperforms conventional oxygen therapy for patients with hypercapnia [19, 20], and home-based HFNC can also improve the quality of life for patients with stable chronic obstructive pulmonary disease [21]. Nevertheless, our results indicate that HFNC cannot replace noninvasive ventilator for patients with mild hypercapnia, although it could be an alternative for patients with poor tolerance to noninvasive ventilation.

Nearly half of the patients with HFNC failure were intubated within 48 hours of treatment $[5,6]$, while increased mortality was found among patients with delayed intubation due to HFNC failure in a retrospective study [22]. In our study, the differences in intubation rates between the two groups were also significantly enlarged with the prolongation of the treatment. It is also suggested that improper high flow therapy may delay intubation in patients with hypercapnia. Therefore, the effect of HFNC needs to be evaluated early.

In our study, the changes in physiological parameters within the first 24 hours after the beginning of oxygen therapy in the two groups were recorded. The heart rate and respiratory rate significantly decreased at 12 hours after initiation of HFNC compared with baseline data. Meanwhile, $\mathrm{PaCO}_{2}$ in both the treatment group and the control group decreased during this period. This therapeutic effect is related to the reduction of respiratory activity and oxygen consumption $[23,24]$, which suggests the use of vital sign changes for the prediction of HFNC failure to avoid delayed intubation. 
In recent years, the ROX index has been proposed as a predictor of HFNC failure, consisting of $\mathrm{SpO}_{2}$, $\mathrm{FiO}_{2}$ and respiratory rate [25]. All three parameters are readily available in clinical settings, and their dynamic changes are useful in assessing the success of HFNC. Generally, a ROX index greater than 4.88 indicates the efficacy of HFNC, while a ROX index less than 3.85 indicates the risk of HFNC failure [26]. However, the ROX index does not take into account heart rate change, which is a sensitive physiological parameter in the early stage of respiratory failure, and its added predictive value for HFNC failure has been demonstrated in combination with the ROX index [27]. Therefore, the prediction accuracy of the ROX index needs further evaluation. Until now, no studies have verified the predictive value of the ROX index in patients with hypercapnia.

In this study, $\mathrm{HR} / \mathrm{SpO}_{2}$ was formulated as a predictor incorporating heart rate and pulse oxygen, which is sensitive, non-invasive, and easy to apply. The $\mathrm{HR} / \mathrm{SpO}_{2}$ after $4 \mathrm{~h}$ treatment was calculated to predict 48hour intubation rate. It was found that the predictive performance of the ROX index for 48-hour intubation after the initiation of HFNC yielded an AUC of less than 0.6 , while the $\mathrm{HR} / \mathrm{SpO}_{2}$ achieved a greater, yet modest AUC of 0.660. An optimal cut-off value of the ROX index based on the Youden index leads to poor sensitivity and moderate specificity. In conclusion, the prediction accuracy of HFNC based on early changes in a single physiological parameter is inadequate, algorithmic models combining more clinical and physiological predictors may improve the accuracy of outcome prediction in subsequent studies.

\section{Limitations}

Type 2 respiratory failure is not the main indication of HFNC; as a result, the sample size of HFNC group was substantially reduced in this study. The average values of physiological parameters at each period within 24 hours were calculated, which might be insufficient to reflect real-time acuity. In addition, the results of our study need to be verified by prospective studies.

\section{Conclusions}

High-flow oxygen therapy cannot completely replace non-invasive mechanical ventilation for patients with mild hypercapnia. As opposed to the ROX index, a modest, yet improved predictive performance is demonstrated using $\mathrm{HR} / \mathrm{SpO} 2$ in predicting treatment failure among mild hypercapnia patients receiving HFNC.

\section{Abbreviations}

HFNC: high-flow nasal cannula; NIV: noninvasive ventilation; MIMIC-IV: Medical Information Mart for Intensive Care IV; ICU: intensive care unit; BMI: body mass index; SAPS-II: Simplified Acute Physiology Scoring II; ABG: arterial blood gas; IQR: interquartile range; PSM: propensity score matching; AUC: area under the receiver operating characteristic curve; $\mathrm{ROX}$ index: ratio of $\mathrm{SpO} / \mathrm{FiO} \mathrm{F}_{2}$ to respiratory rate. 


\section{Declarations}

\section{Acknowledgments}

None

\section{Funding}

Effect evaluation and prediction of high-flow nasal cannula oxygen with algorithm model (ZMX2020-121)

\section{Availability of data and materials}

The MIMIC-IV data were available on the project website at https://mimic-iv.mit.edu/.

\section{Authors' contributions}

Lingling Su conceived the idea, interpreted the results and drafted the manuscript. Qinyu Zhao extracted the data, performed the analysis, and helped to revise the manuscript. Yujun Xu囚Weichun Li and Aiping Zhang helped to interpret the results and drafted the manuscript. Taotao Liu helped to conceive the idea, interpreted the results and revise the manuscript. All authors read and approved the final manuscript.

\section{Ethics approval and consent to participate}

The study was an analysis of two third-party anonymized publicly available databases with preexisting institutional review board (IRB) approval.

\section{Consent for publication}

Not applicable

\section{Conflict of interests}

The authors declare that they have no conflict of interests.

\section{References}

1. Nishimura, M., High-flow nasal cannula oxygen therapy in adults. Journal of Intensive Care, 2015. 3(1): p. 15.

2. Groves, N. and A. Tobin, High flow nasal oxygen generates positive airway pressure in adult volunteers. Australian Critical Care, 2007. 20(4): p. 126-131.

3. Chikata, Y., et al., FIO2 in an Adult Model Simulating High-Flow Nasal Cannula Therapy. Respir Care, 2017. 62(2): p. 193-198. 
4. Frat, J.P., et al., High-flow oxygen through nasal cannula in acute hypoxemic respiratory failure. N Engl J Med, 2015. 372(23): p. 2185-96.

5. Hernandez, G., et al., Effect of Postextubation High-Flow Nasal Cannula vs Noninvasive Ventilation on Reintubation and Postextubation Respiratory Failure in High-Risk Patients A Randomized Clinical Trial Supplemental content. JAMA The Journal of the American Medical Association, 2016. 316.

6. Stéphan, F., et al., High-Flow Nasal Oxygen vs Noninvasive Positive Airway Pressure in Hypoxemic Patients After Cardiothoracic Surgery: A Randomized Clinical Trial. JAMA, 2015. 313(23): p. 2331-2339.

7. Yang, P.-L., J.-Q. Yu, and H.-B. Chen, High-flow nasal cannula for acute exacerbation of chronic obstructive pulmonary disease: A systematic review and meta-analysis. Heart \& Lung, 2021. 50(2): p. 252-261.

8. Pantazopoulos, I., et al., Nasal High Flow Use in COPD Patients with Hypercapnic Respiratory Failure: Treatment Algorithm \& Review of the Literature. Copd, 2020. 17(1): p. 101-111.

9. Johnson, A., et al., MIMIC-IV (version 0.4). PhysioNet, 2020.

10. Leite, W., Practical Propensity Score Methods Using R. 2016.

11. Hernández, G., et al., Effect of Postextubation High-Flow Nasal Cannula vs Conventional Oxygen Therapy on Reintubation in Low-Risk Patients: A Randomized Clinical Trial. JAMA, 2016. 315(13): p. 1354-1361.

12. Wang, Y., et al., High-Flow Nasal Cannula vs Conventional Oxygen Therapy for Postcardiothoracic Surgery. Respiratory Care, 2020: p. respcare.07595.

13. Granton, D., et al., High-Flow Nasal Cannula Compared With Conventional Oxygen Therapy or Noninvasive Ventilation Immediately Postextubation: A Systematic Review and Meta-Analysis. Critical Care Medicine, 2020. 48(11): p. e1129-e1136.

14. Parke, R., S. McGuinness, and M. Eccleston, Nasal high-flow therapy delivers low level positive airway pressure. British Journal of Anaesthesia, 2009. 103(6): p. 886-890.

15. Möller, W., et al., Nasal High Flow Clears Anatomical Dead Space in Upper Airway Models. Journal of applied physiology (Bethesda, Md. : 1985), 2015. 118: p. jap.00934.2014.

16. Van Hove, S.C., et al., An Experimental and Numerical Investigation of CO2 Distribution in the Upper Airways During Nasal High Flow Therapy. Ann Biomed Eng, 2016. 44(10): p. 3007-3019.

17. Bräunlich, J., et al., Nasal high-flow versus noninvasive ventilation in patients with chronic hypercapnic COPD. International Journal of Chronic Obstructive Pulmonary Disease, 2019. Volume 14: p. 
18. Tan, D., et al., High-flow nasal cannula oxygen therapy versus non-invasive ventilation for chronic obstructive pulmonary disease patients after extubation: a multicenter, randomized controlled trial. Crit Care, 2020. 24(1): p. 489.

19. Kim, E., et al., Effectiveness of high-flow nasal cannula oxygen therapy for acute respiratory failure with hypercapnia. Journal of Thoracic Disease, 2018. 10: p. 882-888.

20. Lee, $\mathrm{H}$. , et al., Reduction of PaCO2 by high-flow nasal cannula in acute hypercapnic respiratory failure patients receiving conventional oxygen therapy. Acute and Critical Care, 2019. 34: p. 202-211.

21. Nagata, K., et al., Domiciliary High-Flow Nasal Cannula Oxygen Therapy for Stable Hypercapnic COPD Patients: A Multicenter, Randomized Crossover Trial. Annals of the American Thoracic Society, 2017. 15.

22. Kang, B.J., et al., Failure of high-flow nasal cannula therapy may delay intubation and increase mortality. Intensive Care Medicine, 2015. 41(4): p. 623-632.

23. Roca, O., et al., Patients with New York Heart Association class III heart failure may benefit with high flow nasal cannula supportive therapy: high flow nasal cannula in heart failure. J Crit Care, 2013. 28(5): p. 741-6.

24. Sztrymf, B., et al., Beneficial effects of humidified high flow nasal oxygen in critical care patients: a prospective pilot study. Intensive Care Med, 2011. 37(11): p. 1780-6.

25. Roca, O., et al., An Index Combining Respiratory Rate and Oxygenation to Predict Outcome of Nasal High Flow Therapy. American Journal of Respiratory and Critical Care Medicine, 2018. 199.

26. Spinelli, E., O. Roca, and T. Mauri, Dynamic assessment of the ROX index during nasal high flow for early identification of non-responders. Journal of Critical Care, 2020. 58: p. 130-131.

27. Goh, K., et al., Early prediction of high flow nasal cannula therapy outcomes using a modified ROX index incorporating heart rate. Journal of Intensive Care, 2020. 8.

\section{Tables}

Table 1 Baseline data and prognosis of patients with mild hypercapnia in the two groups 


\begin{tabular}{|c|c|c|c|c|c|c|c|c|}
\hline & \multicolumn{4}{|c|}{ Before PSM } & \multicolumn{4}{|c|}{ After PSM } \\
\hline & All & $\begin{array}{l}\text { HFNC } \\
\text { group }\end{array}$ & $\begin{array}{l}\text { NIV } \\
\text { group }\end{array}$ & $\begin{array}{l}\text { P } \\
\text { Value }\end{array}$ & All & $\begin{array}{l}\text { HFNC } \\
\text { group }\end{array}$ & $\begin{array}{l}\text { NIV } \\
\text { group }\end{array}$ & $\begin{array}{l}\mathrm{P} \\
\text { Value }\end{array}$ \\
\hline \multirow[t]{2}{*}{ Age } & 67.6 & 68.9 & 66.8 & 0.525 & 67.6 & 68.8 & 66.1 & 0.392 \\
\hline & $\begin{array}{l}{[57.7} \\
78.2]\end{array}$ & $\begin{array}{l}{[57.3,} \\
78.9]\end{array}$ & $\begin{array}{l}{[58.0,} \\
77.4]\end{array}$ & & $\begin{array}{l}{[56.9} \\
78.6]\end{array}$ & $\begin{array}{l}{[57.9} \\
79.5]\end{array}$ & $\begin{array}{l}{[56.2,} \\
77.2]\end{array}$ & \\
\hline Male & $\begin{array}{l}196 \\
(51.7)\end{array}$ & $\begin{array}{l}77 \\
(57.9)\end{array}$ & $\begin{array}{l}119 \\
(48.4)\end{array}$ & 0.096 & $\begin{array}{l}114 \\
(53.8)\end{array}$ & $\begin{array}{l}60 \\
(56.6)\end{array}$ & $\begin{array}{l}54 \\
(50.9)\end{array}$ & 0.491 \\
\hline BMI & $\begin{array}{l}32.3 \\
(12.0)\end{array}$ & $\begin{array}{l}28.1 \\
(7.5)\end{array}$ & $\begin{array}{l}34.7 \\
(13.3)\end{array}$ & $<0.001$ & $\begin{array}{l}28.9 \\
(8.4)\end{array}$ & $\begin{array}{l}28.3 \\
(7.7)\end{array}$ & $\begin{array}{l}29.4 \\
(9.1)\end{array}$ & 0.402 \\
\hline \multirow[t]{2}{*}{ Charlson score } & 6.0 & 5.0 & 6.0 & 0.032 & 6.0 & 5.0 & 6.0 & 0.397 \\
\hline & $\begin{array}{l}{[4.0,} \\
8.5]\end{array}$ & $\begin{array}{l}{[4.0,} \\
8.0]\end{array}$ & $\begin{array}{l}{[4.0,} \\
9.0]\end{array}$ & & $\begin{array}{l}{[4.0,} \\
8.0]\end{array}$ & $\begin{array}{l}{[4.0,} \\
8.0]\end{array}$ & $\begin{array}{l}{[4.0,} \\
8.0]\end{array}$ & \\
\hline \multirow[t]{2}{*}{ SPAP-II score } & 35.0 & 35.0 & 35.5 & 0.981 & 36.0 & 36.0 & 36.5 & 0.634 \\
\hline & $\begin{array}{l}{[27.0} \\
44.0]\end{array}$ & $\begin{array}{l}{[27.0} \\
45.0]\end{array}$ & $\begin{array}{l}{[27.0} \\
44.0]\end{array}$ & & $\begin{array}{l}{[27.0} \\
44.0]\end{array}$ & $\begin{array}{l}{[27.0} \\
44.0]\end{array}$ & $\begin{array}{l}{[27.0} \\
44.0]\end{array}$ & \\
\hline \multicolumn{9}{|c|}{ Baseline physiological parameters } \\
\hline Heart rate & $\begin{array}{l}93.0 \\
(19.1)\end{array}$ & $\begin{array}{l}97.6 \\
(17.3)\end{array}$ & $\begin{array}{l}90.5 \\
(19.5)\end{array}$ & 0.001 & $\begin{array}{l}94.8 \\
(18.2)\end{array}$ & $\begin{array}{l}96.0 \\
(16.6)\end{array}$ & $\begin{array}{l}93.5 \\
(19.6)\end{array}$ & 0.342 \\
\hline Respiratory rate & $\begin{array}{l}21.4 \\
(5.5)\end{array}$ & $\begin{array}{l}22.5 \\
(5.6)\end{array}$ & $\begin{array}{l}20.8 \\
(5.3)\end{array}$ & 0.006 & $\begin{array}{l}22.1 \\
(5.9)\end{array}$ & $\begin{array}{l}22.3 \\
(5.7)\end{array}$ & $\begin{array}{l}22.0 \\
(6.1)\end{array}$ & 0.714 \\
\hline MBP & $\begin{array}{l}80.1 \\
(15.8)\end{array}$ & $\begin{array}{l}80.1 \\
(14.4)\end{array}$ & $\begin{array}{l}80.2 \\
(16.5)\end{array}$ & 0.967 & $\begin{array}{l}79.6 \\
(14.2)\end{array}$ & $\begin{array}{l}80.2 \\
(14.3)\end{array}$ & $\begin{array}{l}79.1 \\
(14.2)\end{array}$ & 0.563 \\
\hline $\mathrm{pH}$ & $\begin{array}{l}7.33 \\
(0.08)\end{array}$ & $\begin{array}{l}7.35 \\
(0.06)\end{array}$ & $\begin{array}{l}7.32 \\
(0.08)\end{array}$ & 0.007 & $\begin{array}{l}7.34 \\
(0.07)\end{array}$ & $\begin{array}{l}7.34 \\
(0.06)\end{array}$ & $\begin{array}{l}7.34 \\
(0.08)\end{array}$ & 0.961 \\
\hline \multirow[t]{2}{*}{$\mathrm{PaO}_{2}$} & 83.0 & 74.5 & 86.5 & 0.052 & 82.0 & 77.0 & 84.5 & 0.146 \\
\hline & $\begin{array}{l}{[68.0} \\
120.3]\end{array}$ & $\begin{array}{l}\text { [65.0, } \\
122.0]\end{array}$ & $\begin{array}{l}{[71.3} \\
119.8]\end{array}$ & & $\begin{array}{l}\text { [68.0, } \\
119.8]\end{array}$ & $\begin{array}{l}\text { [63.0, } \\
122.0]\end{array}$ & $\begin{array}{l}\text { [73.8, } \\
119.0]\end{array}$ & \\
\hline \multirow[t]{2}{*}{$\mathrm{PaCO}_{2}$} & 50.5 & 49.5 & 50.5 & 0.071 & 49.3 & 49.8 & 48.8 & 0.254 \\
\hline & $\begin{array}{l}\text { [47.3, } \\
58.0]\end{array}$ & $\begin{array}{l}{[46.5,} \\
57.0]\end{array}$ & $\begin{array}{l}\text { [48.8, } \\
58.0]\end{array}$ & & $\begin{array}{l}{[46.5} \\
57.3]\end{array}$ & $\begin{array}{l}{[46.8} \\
57.5]\end{array}$ & $\begin{array}{l}{[46.5} \\
56.5]\end{array}$ & \\
\hline \multirow[t]{2}{*}{$\mathrm{SpO}_{2}$} & 95.0 & 95.0 & 95.8 & 0.115 & 95.3 & 95.3 & 95.3 & 0.518 \\
\hline & $\begin{array}{l}{[93,} \\
98.5]\end{array}$ & $\begin{array}{l}\text { [92.0, } \\
97.3]\end{array}$ & $\begin{array}{l}\text { [93.8, } \\
97.5]\end{array}$ & & $\begin{array}{l}\text { [92.8, } \\
97.5]\end{array}$ & $\begin{array}{l}\text { [92.5, } \\
97.5]\end{array}$ & $\begin{array}{l}{[93.0} \\
97.3]\end{array}$ & \\
\hline \multirow[t]{2}{*}{$\mathrm{PaO}_{2} / \mathrm{FiO}_{2}$} & 216.0 & 200.1 & 235.3 & 0.065 & 202.7 & 196.3 & 220.5 & 0.453 \\
\hline & $\begin{array}{l}{[180.4,} \\
307.2]\end{array}$ & $\begin{array}{l}{[175.3,} \\
256.0]\end{array}$ & $\begin{array}{l}\text { [187.5, } \\
315.0]\end{array}$ & & $\begin{array}{l}{[178.3,} \\
273.8]\end{array}$ & $\begin{array}{l}{[176.8,} \\
249.3]\end{array}$ & $\begin{array}{l}{[179.8,} \\
287.0]\end{array}$ & \\
\hline
\end{tabular}




\begin{tabular}{|c|c|c|c|c|c|c|c|c|}
\hline \multicolumn{9}{|l|}{ Outcome } \\
\hline $\begin{array}{l}\text { Intubation rate } \\
\text { at } 48 \text { hours }\end{array}$ & $\begin{array}{l}44 \\
(11.6)\end{array}$ & $\begin{array}{l}23 \\
(17.3)\end{array}$ & $21(8.5)$ & 0.018 & $\begin{array}{l}24 \\
(11.3)\end{array}$ & $\begin{array}{l}15 \\
(14.2)\end{array}$ & $9(8.5)$ & 0.278 \\
\hline $\begin{array}{l}\text { Intubation rate } \\
\text { at } 28 \text { days }\end{array}$ & $\begin{array}{l}69 \\
(18.2)\end{array}$ & $\begin{array}{l}37 \\
(27.8)\end{array}$ & $\begin{array}{l}32 \\
(13.0)\end{array}$ & $<0.001$ & $\begin{array}{l}43 \\
(20.3)\end{array}$ & $\begin{array}{l}28 \\
(26.4)\end{array}$ & $\begin{array}{l}15 \\
(14.2)\end{array}$ & 0.029 \\
\hline $\begin{array}{l}\text { Mortality at } 28 \\
\text { days }\end{array}$ & $\begin{array}{l}46 \\
(12.1)\end{array}$ & $\begin{array}{l}24 \\
(18.1)\end{array}$ & $22(8.9)$ & 0.009 & $\begin{array}{l}28 \\
(13.2)\end{array}$ & $\begin{array}{l}19 \\
(17.9)\end{array}$ & $9(8.5)$ & 0.043 \\
\hline \multirow{2}{*}{$\begin{array}{l}\text { Time to } \\
\text { intubation, } \\
\text { hours }\end{array}$} & 19.2 & 19.5 & 19.2 & 0.647 & 21.0 & 30.8 & 19.2 & 0.610 \\
\hline & $\begin{array}{l}{[5.8,} \\
102.3]\end{array}$ & $\begin{array}{l}{[7.8,} \\
112.3]\end{array}$ & $\begin{array}{l}{[2.96} \\
70.7]\end{array}$ & & $\begin{array}{l}{[5.4} \\
126.0]\end{array}$ & $\begin{array}{l}{[7.5,} \\
125.3]\end{array}$ & $\begin{array}{l}{[2.5,} \\
145.2]\end{array}$ & \\
\hline \multirow{2}{*}{$\begin{array}{l}\text { Hospital LOS, } \\
\text { days }\end{array}$} & 9.5 & 10.6 & 9.0 & 0.007 & 10.1 & 10.2 & 10.0 & 0.776 \\
\hline & $\begin{array}{l}{[6.1} \\
15.8]\end{array}$ & $\begin{array}{l}{[6.7} \\
20.8]\end{array}$ & $\begin{array}{l}{[5.8,} \\
13.9]\end{array}$ & & $\begin{array}{l}{[6.5} \\
16.1]\end{array}$ & $\begin{array}{l}{[6.3,} \\
16.9]\end{array}$ & $\begin{array}{l}{[6.7} \\
15.8]\end{array}$ & \\
\hline \multirow[t]{2}{*}{ ICU LOS, days } & 3.2 & 4.4 & 2.9 & $<0.001$ & 4.1 & 4.4 & 3.3 & 0.019 \\
\hline & $\begin{array}{l}{[1.8,} \\
6.4]\end{array}$ & $\begin{array}{l}{[2.3} \\
8.1]\end{array}$ & $\begin{array}{l}{[1.6,} \\
5.7]\end{array}$ & & $\begin{array}{l}{[2.1} \\
7.2]\end{array}$ & $\begin{array}{l}{[2.6,} \\
7.7]\end{array}$ & $\begin{array}{l}{[1.8,} \\
6.3]\end{array}$ & \\
\hline
\end{tabular}

Table 2 Changes of physiological parameters of the two groups patients within 24 hours 


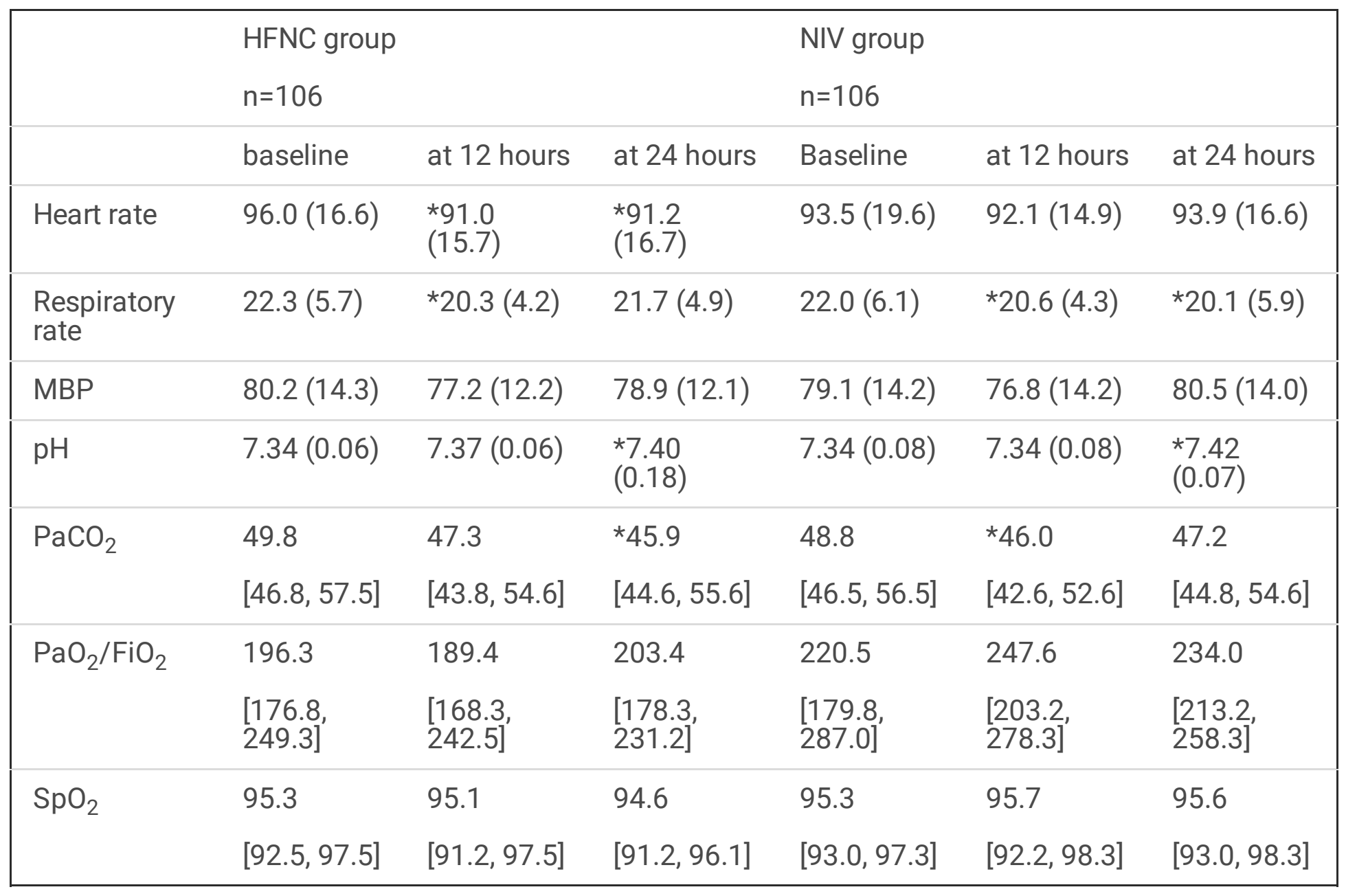

* $P<0.05$ compared to baseline values

Table 3 Predicts the performances of $\mathrm{HR} / \mathrm{SpO}_{2}$ and $\mathrm{ROX}$ index at 4 hours after HFNC for 48-hour intubation

\begin{tabular}{|c|c|c|c|c|c|c|}
\hline & AUC & $P$ value & Cutoff value & Youden index & Sensitivity & Specificity \\
\hline $\mathrm{HR} / \mathrm{SpO}_{2}$ & 0.660 & $P<0.01$ & 1.086 & 0.308 & 0.571 & 0.736 \\
\hline ROX index & 0.589 & & 3.680 & 0.350 & 0.444 & 0.906 \\
\hline
\end{tabular}

\section{Figures}




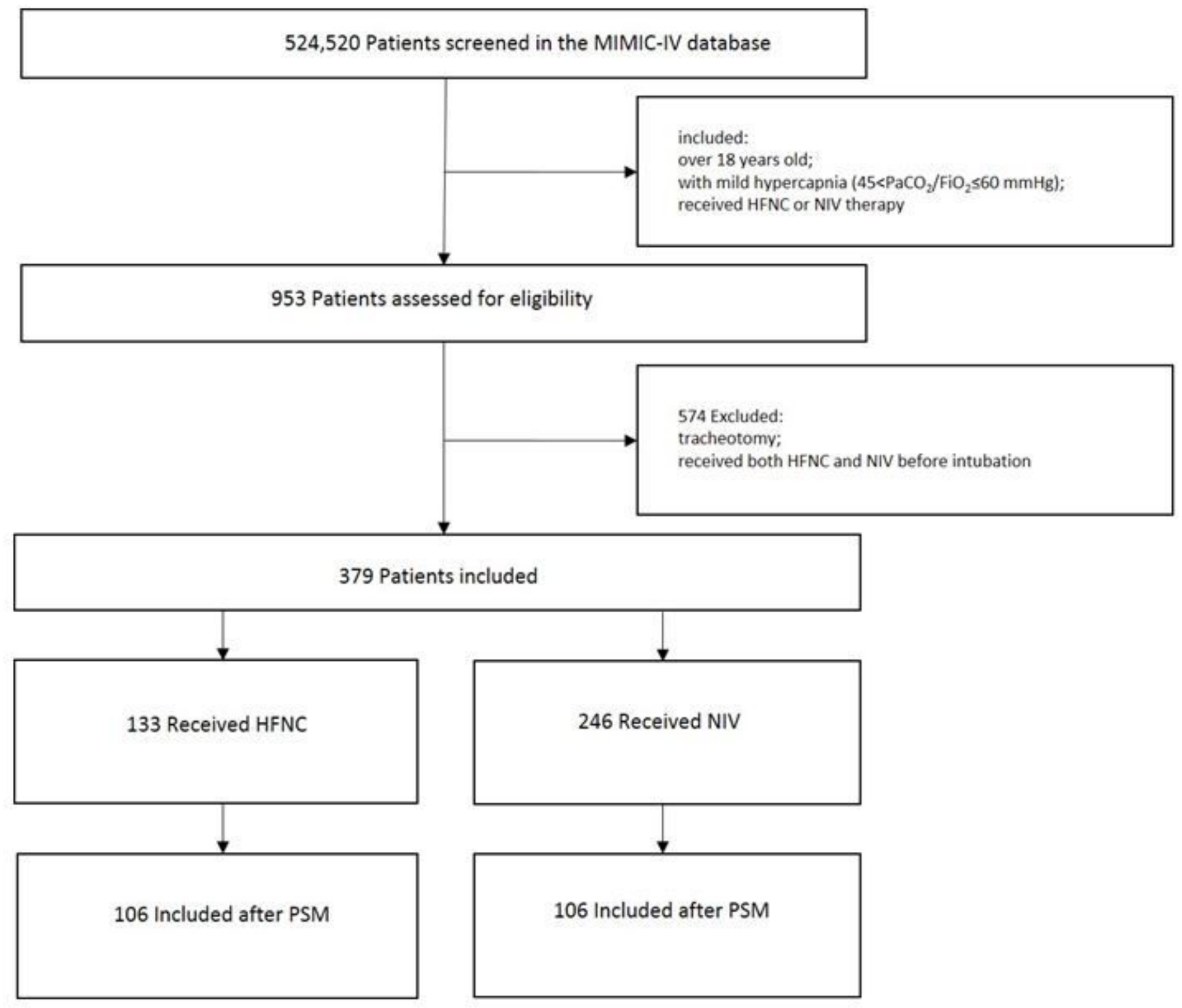

\section{Figure 1}

Flow chart showing the classification and propensity score matching of mild hypercapnic patients 

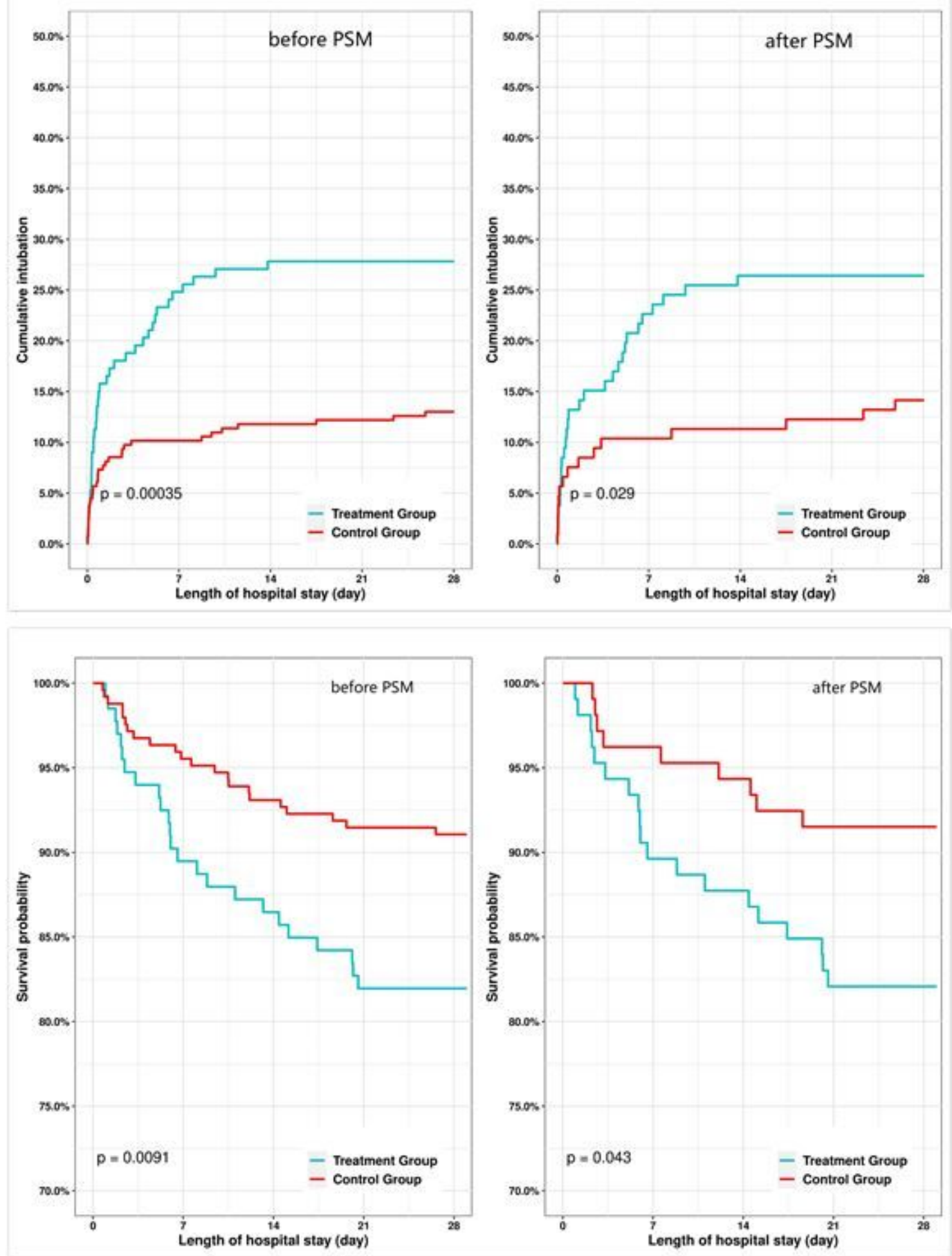

\section{Figure 2}

Survival curve and cumulative intubation curve of patients with mild hypercapnia before and after PSM 

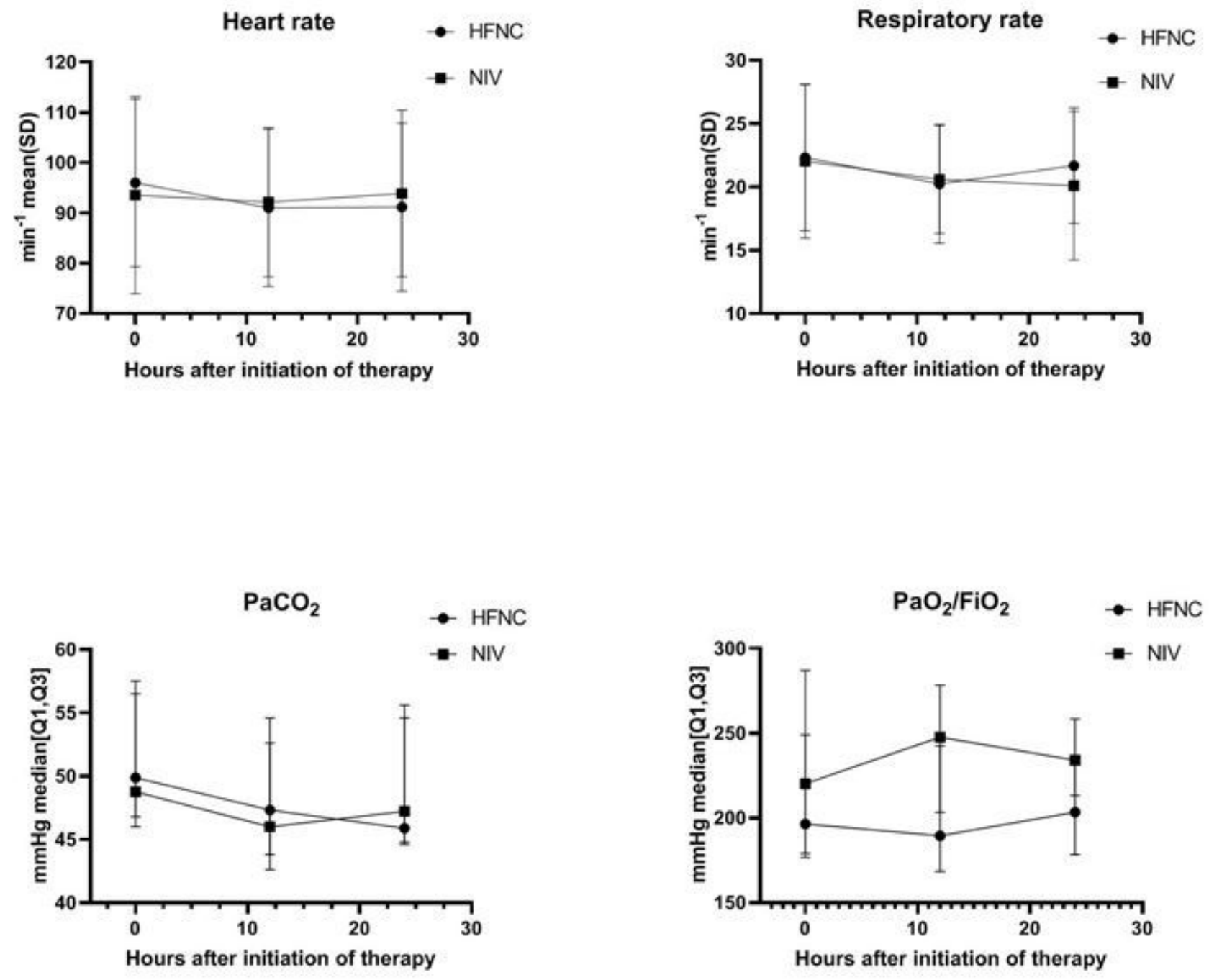

Figure 3

Changes in physiological parameters within 24 hours among the two groups patients 


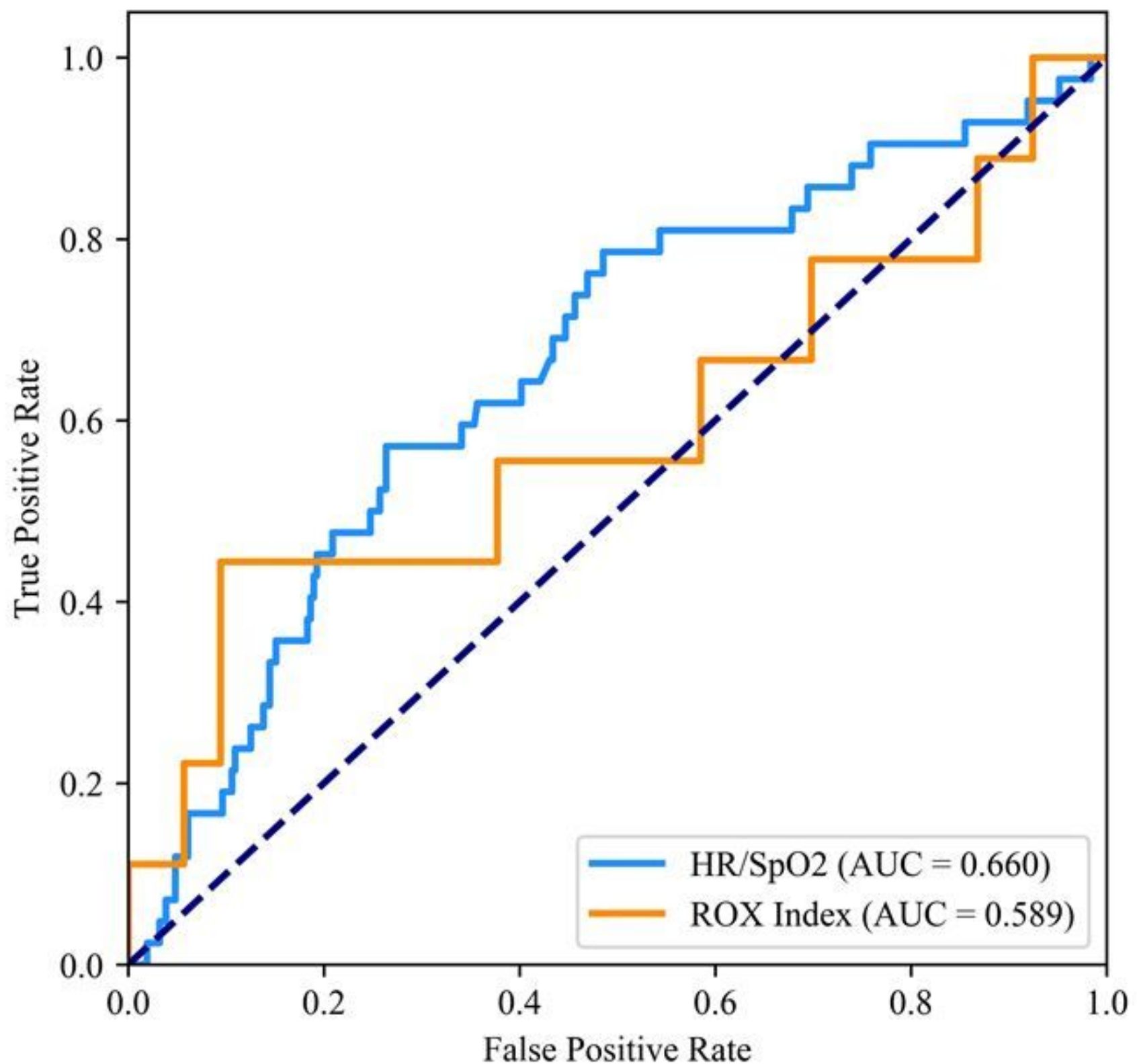

Figure 4

The ROC curves of HR/SpO2 and ROX index for 48-hour intubation prediction in the HFNC group 